DOI: 10.12731/2070-7568-2017-3-124-133

УДК 338.5

\title{
ТРАНСФЕРТНАЯ ЦЕНА КАК ИНСТРУМЕНТ НЕЛЕГАЛЬНОГО ПОВЕДЕНИЯ ХОЛДИНГА
}

\author{
Елистратова E.B.
}

С точки зрения институциионального подхода трансфертное ценообразование определяется как взаимоотношение, строящееся на условиях, льготных по отношению к рынку, которое в свою очередь является определенным инструментом регулирования хозяйственных связей внутри холдинга. Следует отметить, что внутри холдинга существует свой собственный внутренний рынок, а значит, существует внутренняя торговля, следовательно, имеет место и трансфертное иеенооразование. Использование трансфертных изен возможно только при наличии нескольких аффилированных лии, чем характеризуется структура всех современных холдинговых компаний. Положительный аспект использования трансфертных цен связан с повышением эффективности управления и конкурентоспособности холдинга. Однако многие международные компании прибегают к манипулированию трансфертныли цеенами с ичелью оптимизации своих налоговых обязательств. Следовательно, выявлена необходимость снижения налоговых рисков при использовании трансфертных иен, необходимость контроля за трансфертным иенообразованием, прежде всего контроль за сделками между аффилированными лицами и обозначены меры государства по ограничению трансфертного чзенообразования.

Цель определить нелегальное поведение холдинга в современных условиях рыночного хозяйствования за счет использования трансфертных иен.

Метод или методология проведения работы: в статье использовались сравнительный метод, а также методы формальной логики (анализ и синтез, индукция и дедукиия, абстракиฺия, обобщение). 
Результаты: выявлень и проанализированы условия, при которых трансфертные цены выступают как нелегальный инструмент функиионирования холдинговых компаний.

Область применения результатов: полученные результаты исследования могут быть использовань в работе компаниями, применяющих трансфертное ценообразование для эффективного управления функиионированием компаний холдинга.

Ключевые слова: трансфертная цчена; трансфертное иченообразование; холдинг; налог; минимизачия налогов; уклонение от налогов; трансакичи; аффилированные лица.

\section{TRANSFER PRICE AS TOOL OF ILLEGAL BEHAVIOUR OF HOLDING}

\section{Elistratova E.V.}

From the point of view of institutional approach transfer pricing is defined as the relationship which is based on conditions, preferential in relation to the market which in turn is a certain instrument of regulation of economic communications in holding. It should be noted that within the holding there is its own domestic market, which means that there is internal trade, therefore, transfer pricing takes place. The use of transfer prices is only possible when you have multiple affiliates, what characterizes the structure of all modern holding companies. The positive aspect of using transfer prices is related to increase of efficiency of management and competitiveness of the holding. However, many international companies have resorted to the manipulation of transfer prices to optimize their tax liabilities. Therefore, to identify the need to reduce tax risks in using transfer prices, the need for transfer pricing control, especially the control over transactions between affiliates and designated state measures to limit transfer pricing.

Purpose: identify the illegal behavior of the holding through the use of transfer prices.

Results: the advantages and costs of using transfer prices by holding companies were revealed and justified. 
Practical implications: revealed and analyzed the conditions under which transfer prices act as an illegal instrument for the operation of holding companies.

Keywords: transfer price; transfer pricing; holding; tax; tax minimization; tax evasion; the transaction; affiliates.

В настоящее время актуальным является вопрос о теоретически и практически эффективных механизмах трансфертного ценообразования для холдинговых компаний. Трансфертное ценообразование это взаимоотношение, строящееся на условиях, льготных по отношению к рынку, которое, в свою очередь, является определенным инструментом регулирования хозяйственных связей внутри холдинговых образований. Но в данном определении никак не отражено, используется ли трансфертная цена структурами холдинга или совсем несвязанными с ним сторонами, не уточняется территориальная принадлежность компаний. В более развернутом виде, трансфертное ценообразование состоит в манипулировании расходами, доходами и затратами в сделках между аффилированными лицами способом, отличным от тех, которые были бы использованы в трансакциях, совершенных на рыночных условиях. Объективная причина возникновения трансфертных цен связана с комбинированием групп компаний в холдинговые компании, которые неизбежно взаимодействуют, заключают между собой трансакции, в процессе международного бизнеса.

В России систему использования трансфертных цен использует малый процент холдинговых компаний, в отличие от зарубежной практики использования трансфертного ценообразования. В российском законодательстве нет запрета на применение трансфертных цен. Согласно ст. 421 и ст. 424 Гражданского кодекса РФ стороны могут производить расчеты по договорам по любой цене. Однако для целей налогообложения должна быть принята во внимание рыночная цена сделки. Иначе говоря, продукция может быть поставлена по цене в 10 раз ниже или выше рыночной, но налоги должны быть уплачены с рыночной цены товара (при 
этом допустимое отклонение от нее составляет 20\%) [6, с. 62]. Одним из основных преимуществ внедрения трансфертных цен является налоговый мотив, перевод денежных средств в подразделение, расположенное в оффшорных зонах, где существуют налоговые льготы или вообще имеется полное освобождение от уплаты налогов $[1$, с. 40]. Наличие этого признака позволяет нам трактовать трансфертные цены как способ обхода налоговых законов, занижения размера налоговых обязанностей. Следовательно, использование трансфертных цен в целях уклонения от уплаты налогов позволяет считать их инструментом нелегального поведения холдинга, а значит, уменьшение налоговых поступлений в бюджеты РФ. Поскольку для снижения налоговой нагрузки большинство корпораций предрасположены к использованию трансфертных цен, необходимы эффективные инструменты государственного контроля, дающие возможность определить правомерность использования цен при заключении сделок между аффилированными лицами [3, с. 157]. За уровнем трансфертных цен холдинга в развитых странах, в отличие от других стран, устанавливается контроль налоговых органов, который направлен на недопущение снижения налоговых обязательств холдинга через использование трансфертных цен. Поэтому налоговое законодательство многих стран ограничивает свободу установления трансфертных цен. В связи с этим, контроль трансфертного ценообразования - это, прежде всего контроль над сделками между аффилированными лицами [13, с. 58]. Остается открытым вопрос о порядке признания лиц аффилированными или взаимозависимыми [8, с. 14]. Если ранее взаимозависимость юридических лиц определялась через непосредственное или косвенное участие одной организации в другой при доле такого участия более $20 \%$, то с введением новой статьи НК РФ данный порог был увеличен до $25 \%$, а также установлен целый ряд других оснований для признания субъектов взаимозависимыми [14, с. 29]. На основе вышеизложенного можно сделать вывод о том, что использование в трансакциях трансфертных цен характеризуется нелегальным поведением холдинга, так как в государственном законодатель- 
стве имеются пробелы в виде льготного налогообложения, что позволяет получать выгоду от их умелого использования. Так, в 2012 и 2013 гг. налогоплательщики будут полностью освобождены от штрафных санкций в случае отклонения применяемых ими цен от рыночных. В 2014-2016 гг. размер штрафа составит $20 \%$ от неуплаченной суммы налога, а начиная с 2017 г. - 40\%, но не менее 30 тыс. руб. Если же налогоплательщик представит по запросу налогового органа документальное обоснование (утвержденную методику) рыночного уровня цен, примененных по контролируемой сделке, то штрафные санкции к нему в силу п. 2 ст. 129.3 НК РФ применяться не будут [10, с. 37]. При этом действия налоговых органов должны быть направлены не на ликвидацию трансфертного ценообразования как элемента рыночных отношений, а на максимальное снижение негативного влияния его применения на бюджет страны [15, с. 67].

В настоящее время в связи постоянным ростом конкуренции на многих российских рынках встает вопрос о повышении конкурентоспособности компаний, входящих в холдинг. В западных странах, холдинговые компании, ТНК, ФПГ и другие структуры бизнеса сформировались в результате эволюции экономических отношений. Что касается российской экономики - процесс возникновения холдинговых компаний, произошел в короткие сроки. Рост компаний холдингового типа является одним из главных источников ее эффективности и средством выживания в конкурентной борьбе [4, с. 18]. В сложившихся рыночных условиях используя механизм трансфертного ценообразования можно существенно повысить конкурентоспособность холдинговых компаний на основе механизмов взаимодействий, способствующих согласованию экономических интересов, устранения лишних промежуточных посредников.

Произведенный автором анализ отечественной и зарубежной литературы позволил выявить формы проявления трансфертной цены в условиях функционирования холдинговых компаний:

- во-первых, трансфертная цена как нерыночный инструмент;

- во-вторых, трансфертная цена как нелегальный инструмент. 
Таблицуа 1.

Формы проявления трансфертной цены

\begin{tabular}{|c|c|c|}
\hline & $\begin{array}{c}\text { Трансфертные цены как нерыночный } \\
\text { инструмент }\end{array}$ & $\begin{array}{c}\text { Трансфертные цены } \\
\text { как нелегальный } \\
\text { инструмент } \\
\end{array}$ \\
\hline $\begin{array}{l}\text { Функции } \\
\text { трансфертной } \\
\text { цены }\end{array}$ & $\begin{array}{l}\text { - Управление издержками холдинга; } \\
\text {-Регулирование внутрифирменных } \\
\text { отношений, посредством распределе- } \\
\text { ния ресурсов; } \\
\text { - Распределение рынков сбыта между } \\
\text { различными участниками холдинга; } \\
\text { - Как инструмент контроля транс- } \\
\text { фертные цены обеспечивают до- } \\
\text { стижение плановых показателей по } \\
\text { прибыли, снижение издержек произ- } \\
\text { водства и реализации продукции на } \\
\text { всех этапах производства [5, с.76]; } \\
\text { - Как инструмент управления под- } \\
\text { разделениями холдинга, для дости- } \\
\text { жения высоких финансовых показа- } \\
\text { телей [12]. }\end{array}$ & $\begin{array}{l}\text { - Минимизация нало- } \\
\text { говых платежей; } \\
\text { - Совершение сделок } \\
\text { через компанию-одно- } \\
\text { дневку; }\end{array}$ \\
\hline $\begin{array}{l}\text { Преимущества } \\
\text { для компании }\end{array}$ & $\begin{array}{l}\text { - Оценка вклада каждого } \\
\text { подразделения в прибыль компании; } \\
\text { - Стимулирование руководителей, } \\
\text { обеспечивающих прибыльность того } \\
\text { или иного направления; } \\
\text { - Оптимизация уровня налогообложе- } \\
\text { ния компании [9, с. 38]. }\end{array}$ & $\begin{array}{l}\text { - Аккумулирование } \\
\text { прибыли в сбытовых } \\
\text { структурах, зареги- } \\
\text { стрированных в зонах } \\
\text { с льготным налого- } \\
\text { обложением (офф- } \\
\text { шорные страны), } \\
\text { например, Андорра, } \\
\text { Бермудские острова, } \\
\text { Кайманы, Канарские } \\
\text { острова. }\end{array}$ \\
\hline $\begin{array}{l}\text { Риски для } \\
\text { компании }\end{array}$ & $\begin{array}{l}\text { - Невыгодность внешних инвести- } \\
\text { ций и кредитования таких предпри- } \\
\text { ятий, которые не показывают свою } \\
\text { прибыль; } \\
\text { - Отрицательно сказываться на при- } \\
\text { влечении инвестиций и на конкурен- } \\
\text { тоспособности продукции, особенно } \\
\text { по сравнению с продукцией зарубеж- } \\
\text { ных компаний. }\end{array}$ & $\begin{array}{l}\text { - Проведение нало- } \\
\text { гового контроля, на- } \\
\text { правленного на про- } \\
\text { верку правильности } \\
\text { применения для целей } \\
\text { налогообложения цен } \\
\text { по сделкам между аф- } \\
\text { филированными лица- } \\
\text { ми [2]. }\end{array}$ \\
\hline
\end{tabular}




\begin{tabular}{|l|l|l|}
\hline Риски для & - Ущемление интересов добросовест- & - Уменьшения нало- \\
общества & ных налогоплательщиков [1, с. 39]; & говых поступлений \\
& - Не определен порядок проведения & в бюджеты РФ от ис- \\
& проверок совершения трансакций & пользования холдин- \\
& между аффилированными лицами. & говыми компаниями \\
& & механизмов трансферт- \\
& ного ценообразования. \\
\hline
\end{tabular}

Из таблицы видно, что использование трансфертных цен в отношениях между компаниями холдинга может преследовать не только цель уменьшения налоговое бремя, например, может быть связано с рациональной организацией деятельности компаний холдинга. Положительный аспект применения трансфертных цен может быть обусловлен их ролью как нерыночного инструмента повышения эффективности использования финансовых ресурсов, а также повышением эффективности управления и конкурентоспособности холдинга в целом. В силу своей природы трансфертная цена существенно влияет на отчетные показатели подразделения холдинга (затраты и выручку) и поэтому сама по себе является важным инструментом оценки деятельности компаний холдинга. Как инструмент контроля трансфертные цены обеспечивают достижение плановых показателей по прибыли, снижение издержек производства и реализации продукции на всех этапах производства и движения товара к конечному потребителю.

Менеджеры, стремясь увеличить прибыль своего подразделения, увеличивают прибыль холдинговой компании в целом, т.е. повышается мотивация каждого менеджера, отвечающего за конкретное направление. В идеале трансфертная цена должна позволять руководителю компании принимать оптимальные решения для холдинга в целом. Трансфертное ценообразование представляет собой не только необходимое, но и достаточное условие эффективного функционирования холдинга, т.к. при отсутствии развитой системы трансфертного ценообразования, деятельность и существование холдинга в условиях современного высоко конкурирующего и быстро меняющегося рынка могут потерять всякий смысл. Но трансфертное ценообразование, прежде всего, - это объективная потребность рынка и мощный стимул для развития экономики. И далеко не всегда использование трансфертных цен направлено исключительно на минимизацию налогов, скорее всего, это следствие, дополнительная возможность их использования. 


\section{Список литературы}

1. Артеменко Д.А., Артеменко Г.А. Налоговое консультирование трансфертного ценообразования корпораций// Научный вестник ЮИМ. 2015. №3. С. 38-42.

2. Горина Г.А., Ахмадеев Р.Г. Трансфертное ценообразование и новации налогового контроля [электронный ресурс] // Справочник экономиста. 2013. №3. https://www.profiz.ru/se/3_2013/novacij_ kontrolja/ (дата обращения 30.08.2017).

3. Грундел Л.П. Регулирование трансфертных цен как эффективный инструмент налогового контроля // Проблемы современной экономики. 2014. № 4(52). С. 156-160.

4. Иванова Е.В. Особенности функционирования холдинговых структур в трансформационной экономике России // Вестник ОГУ. 2008. №8 (90). C. 14-19.

5. Иванова Е.В. Сущность трансфертной цены в системе внутрихолдинговых отношений // Формирование рыночного хозяйства: теория и практика. Сборник научных статей. Выпуск X / Под ред. проф. М.Г. Лапаевой; Оренбургский гос. Ун-т. Оренбург: ОГУ, 2010. С. 74-78.

6. Караханян С. Трансфертное ценообразование и современные налоговые реалии // Рынок ценных бумаг. 2008. №15 (366). С. 61-63.

7. Котляров И.Д. О методике идентификации гибридных структур // Вестник НГУЭУ. 2015. № 4. С. 347-356.

8. Плетнева Г. Налоговый контроль трансфертного ценообразования требует ясности // ЭЖ-Юрист. 2014. № 15. С. 14.

9. Просвирина И.И., Вязников С.А. Особенности ценообразования в холдинговых структурах // Молодой ученый. 2016. №10.5. С. 38-40.

10. Чайковская Л.А., Мамрукова О.И. Налоговый контроль за трансфертным ценообразованием: проблемы, новации законодательства и тенденции повышения эффективности // Международный бухгалтерский учет. 2012. 40/238. С. 35-49.

11. Уильямсон О.И. Экономические институты капитализма: фирмы, рынки, «отношенческая» контрактация. СПб. 1996. С. 702.

12. Хомутов В. Как использовать трансфертные цены для управления компанией [электронный ресурс] // Финансовый директор. 2004. № 7-8. C. 46-54. http://stepconsulting.ru/publ/transfert.shtml 
13. Юрмашев Р.С. Трансфертное ценообразование и контроль за применением трансфертных цен в России // Аудиторские ведомости. 2007. №11. С. 58-68.

14. Шаповалов М.А. Налоговый контроль и трансфертное ценообразование // Финансовое право. 2012. № 9. С. 28-32.

15. Щербакова И.Г. Анализ налогового контроля трансфертного ценообразования на примере управления федеральной налоговой службы по Удмуртской Республике [электронный ресурс] // Вестник Удмуртского университета. Экономика и Право. 2016. Том 26. Выпуск 1. С. 67-73. http://ru.vestnik.udsu.ru/files/originsl_articles/vuu_16_021_10.pdf

\section{References}

1. Artemenko D.A., Artemenko G.A. Nalogovoe konsultirovanie transfertnogo cenoobrazovaniya [Tax consulting transfer pricing corporations]. Scientific Herald of WIM, 2015, no 3, pp. 38-42.

2. Gorina G.A., Ahmadeev R.G. Spravochnik ekonomista. 2013. №3. https://www.profiz.ru/se/3_2013/novacij_kontrolja/

3. Grundel L.P. Regulirovanie transfertnih cen kak effektivniy instrument nalogovogo kontrolya [The regulation of transfer prices as an effective instrument of tax control]. Problems of modern economy, 2014, no 4(52), pp. 156-160.

4. Ivanova E.V. Osobennosti funcsionirovaniya holdingovig struktur v transformasionnoy economice Rossii [Peculiarities of functioning of holding structures in the transition economy of Russia]. Vestnik OSU, 2008, no 8 (90), pp. 14-19.

5. Ivanova E. V. Suhnost transfertnoy ceny v sisteme vnutriholdingovih otnosheniy [The Essence of transfer prices in the system of intercompany relations]. Formirovanie rynochnogo khozyaystva: teoriya i praktika. Sbornik nauchnykh statey. Vypusk $X$ [Formation of market economy: theory and practice. Collection of scientific articles. The release of X] / Under the editorship of Professor M.G. Lapaeva; Orenburg state University. Orenburg: OSU 2010, pp. 74-78.

6. Karakhanyan S. Transfertnoe senoobrazovanie I sovremennie nalogovie realii [Transfer pricing and modern tax realities]. Rynok tsennykh bumag, 2008, no 15 (366), pp. 61-63.

7. Kotlyarov I.D. Vestnik NGUEU. 2015. no 4, pp. 347-356. 
8. Pletneva G. EJ-Urist. 2014. No 15, pp. 14.

9. Prosvirina I.I., Vyaznikov. S.A. Osobennosti senoobrazovaniya v holdingovih structurah [Price formation in holding structures]. Young scientist, 2016, no 10.5, pp. 38-40.

10. Chaykovskaya L. A., Mamrukova O.I. Nalogoviy control za transfertnim cenoobrazovaniem: problemi, novacii zakonodatelstva i tendensii povisheniya effektivnosti [Tax control over transfer pricing: problems, innovations of legislation and the increasing effectiveness]. Mezhdunarodnyy bukhgalterskiy uchet, 2012, 40/238, pp. 35-49.

11. Williamson O.E. Ekonomicheskie instituti kapitalizma: Firmi, rinki «otnoshencheskaya» kontraktasiya [The economic institutions of capitalism: firms, markets, "relational" Contracting]. SPb., 1996, 702 p.

12. Homutov V. Finansovyy direktor, 2004, no 7-8, pp. 46-54. http://stepconsulting.ru/publ/transfert.shtml

13. Urmashev R.S. Transfertnoe senoobrazovanie i control za primeneniem transfertnih cen $\mathrm{v}$ Rossii [Transfer pricing and control over the use of transfer pricing in Russia]. Audit statements, 2007, no 11, pp. 58-68.

14. Shapovalov M.A. Finansovoe pravo, 2012, no 9, pp. 28-32.

15. Cherbakova I.G. Vestnik Udmurtskogo universiteta. Ekonomika I Pravo, 2016, V. 26, № 1, pp. 67-73. http://ru.vestnik.udsu.ru/files/originsl_articles/vuu_16_021_10.pdf

\section{ДАННЫЕ ОБ АВТОРЕ}

Елистратова Евгения Васильевна, старший преподаватель кафедры «Экономическая теория»

Оренбургский государственный университет

пр. Победы, 13, г. Оренбург Оренбургская область, 460018, Российская Федерация elistratova13@gmail.com

\section{DATA ABOUT THE AUTHOR}

Elistratova Evgeniya Vasilevna, Senior Lecturer of the Department "Economic theory"

Orenburg Region State University

13, Pobedy Pr., Orenburg, Orenburg region, 460018, Russian Federation elistratova13@gmail.com 